\title{
Temporal dynamics of the very premature infant gut dominant microbiota
}

Fabien Aujoulat ${ }^{1 \dagger}$, Laurent Roudière ${ }^{2 \dagger}$, Jean-Charles Picaud ${ }^{3}$, Aurélien Jacquot ${ }^{5}$, Anne Filleron ${ }^{1,4}$, Dorine Neveu ${ }^{6}$, Thierry-Pascal Baum ${ }^{6}$, Hélène Marchandin ${ }^{1,7}$ and Estelle Jumas-Bilak ${ }^{1,8^{*}}$

\begin{abstract}
Background: The very-preterm infant gut microbiota is increasingly explored due to its probable role in the development of life threatening diseases. Results of high-throughput studies validate and renew the interest in approaches with lower resolution such as PCR-Temporal Temperature Gel Electrophoresis (TTGE) for the follow-up of dominant microbiota dynamics. We report here an extensive longitudinal study of gut colonization in very preterm infants. We explored by 165 rDNA-based PCR-TTGE a total of 354 stool specimens sampled during routine monitoring from the $1^{\text {st }}$ to the $8^{\text {th }}$ week of life in 30 very pre-term infants born before 30 weeks of gestational age.

Results: Combining comparison with a diversity ladder and sequencing allowed affiliation of 50 Species-Level Operational Taxonomic Units (SLOTUs) as well as semi-quantitative estimation of Operational Taxonomic Units (OTUs). Coagulase-negative staphylococci, mainly the Staphylococcus epidermidis, was found in all the infants during the study period and was the most represented (75.7\% of the SLOTUs) from the first days of life. Enterococci, present in 60\% of the infants were early, highly represented and persistent colonizers of the premature gut. Later Enterobacteriaceae and the genus Clostridium appeared and were found in 10 (33\%) and 21 infants (70\%), respectively. We showed a high representation of Veillonella in more than a quarter of the infants and being able to persistently colonize premature gut. The genera Anaerococcus, Aquabacterium, Bacillus, Bifidobacterium, Corynebacterium, Micrococcus, Oceanobacillus, Propionibacterium, Pseudomonas, Rothia, Sarcina, Sneathia and Streptococcus were observed as transient or persistent colonizers, each genus being found in a minority of infants.

Conclusions: Despite low resolution, PCR-TTGE remains complementary to high-throughput sequencing-based approaches because it allows the follow-up of dominant bacteria in gut microbiota in a large longitudinal cohorts of preterm neonates. We described the development of pre-term gut microbiota that should be now replaced regarding the functional role of major OTUs.
\end{abstract}

Keywords: Extremely low birth weight Infant, Stool, Microbiota, Follow-up, PCR-TTGE, Diversity, Dynamics, Staphylococcus, Enterococcus, Clostridium, Enterobacteriaceae, Veillonellaceae

\section{Background}

Soon after birth, bacteria colonize the previously germfree infant gastrointestinal tract. The colonizing bacteria participate to the barrier effect of the gut mucosa, facilitate carbohydrate assimilation, and modulate the immune

\footnotetext{
* Correspondence: ebilak@univ-montp1.fr

${ }^{\dagger}$ Equal contributors

'Université Montpellier 1, UMR 5119 ECOSYM, Equipe Pathogènes et

Environnements Unité de Bactériologie, U.F.R. des Sciences pharmaceutiques et biologiques, 15, Avenue Charles Flahault, BP 14491, Montpellier, Cedex 5 34093, France

${ }^{8}$ Centre Hospitalier Universitaire de Montpellier, Laboratoire d'Hygiène hospitalière, 778, Rue de la Croix Verte, Montpellier 34000, France Full list of author information is available at the end of the article
}

system. Therefore, the establishment and dynamics of gut microbiota have a great influence on the healthy development of the infant. Microbiota composition and its dynamics have been described for healthy neonates $[1,2]$ and to a lesser extent for pre-term neonates [3-5]. Knowledge regarding the gut microbiota dynamics in very premature infants ( $<30$ weeks of gestation) remains limited whereas digestive complications are frequent and life-threatening in this population, particularly in the case of necrotizing enterocolitis (NEC) [6]. In addition, disequilibrium in the gut bacterial community might increase the risk of late-onset sepsis (LOS) after disruption of the immature mucosal barrier, resulting in translocation of luminal contents [7]. 
The impact of some bacterial species on the infant health and growth has been underlined [8]. For instance, De la Cochetière et al. showed by a molecular-based method that Clostridium perfringens appeared in the first 2 weeks of life in 3 infants who later developed a NEC [9]. More recently, unclassified bacteria of the family Enterobacteriaceae appeared to be associated with NEC [10]. On the opposite, bifidobacteria are considered to enhance installation and equilibrium of the microbiota, especially by maintaining the intestinal microbial balance and inhibiting the growth of pathogens $[11,12]$. However, the role of a single bacterium in health or diseases is doubtful $[13,14]$ and one hypothesis is that inappropriate dynamics of gut colonization involving distortion and disequilibrium of the microbiota can cause NEC $[8,10]$ and LOS [7].

Knowledge about the microbiota development arising from the chronological follow-up of extremely premature infants stool bacteria was initially based on culture studies. Among numerous studies, Sakata et al. (1985) [3] reported the longer study period (day 1 to day 49) but included only 7 infants. Other studies usually included more infants (26 to 99) with variable median gestational age (GA) (26 to 33 weeks) and follow-up period (one week to one month) [15-25]. Molecular methods have complemented or replaced cultural approaches for the study of complex ecosystems such as human resident microbiota [26]. The $16 \mathrm{~S}$ ribosomal RNA (16S rRNA) gene-based PCR in association with sequencespecific separation tools such as T-RFLP (Terminal Restriction Fragment Length Polymorphism) [27,28], DGGE (Denaturing Gradient Gel Electrophoresis) [10,29-31] and TTGE (Temporal Temperature Gradient Gel Electrophoresis) $[4,9,24,32,33]$ were used for studying bacterial gut communities in the premature population. More recently, studies based on pyrosequencing technology used deeper molecular analysis of the gut-associated microbiota of preterm infants. These studies revealed previously unappreciated biodiversity $[5,31,34,35]$, including that of viruses and fungi [35]. However, this descriptive power is often underexploited, most high-throughput sequencing-based data being interpreted at the phylum level or with a focus on dominant Operational Taxonomic Units (OTUs) [10,31]. Exception is a recent metagenomic study that track strain level variations in 11 fecal samples chronologically collected in one premature infant [36 ref].

Considering dominant OTUs and high-level taxonomic ranks, fingerprint-based methods and high-throughput sequencing gave roughly congruent results [35]. Therefore, results of high-throughput studies validate approaches with lower resolution such as PCR-TTGE for dominant OTUs detection. PCR-TTGE allows a snapshot of the dominant microbiota and a monitoring of microbiota dynamics by identification of the dominant OTUs and analysis of multiple serial specimens in large population of preterm infants. We previously proposed an optimized approach for studying premature infant gut microbiota by PCR-TTGE and showed its reliability for bacterial identification and semi-quantitative estimation by comparison with culture [24]. This approach demonstrated a positive relationship between the diversity of the intestinal microbiota, digestive tolerance and weight gain in very preterm infants [33].

The aim of this longitudinal study was to describe the temporal dynamics of bacterial diversity in very preterm infant stools by a low-resolution focusing on dominant gut microbiota. Thirty infants born before 30 weeks of gestation were included, and a mean of 12 stool samples per infant were obtained chronologically from the $1^{\text {st }}$ to the $8^{\text {th }}$ week of life. A total of 354 stool samples were collected.

\section{Results and discussion}

\section{Diversity of species-level operational taxonomic units}

We analyzed 354 samples obtained from 30 patients. Figure 1 shows a representative TTGE gel corresponding to the chronological follow-up of the gut microbiota of the infant D. No DNA amplification was obtained for 14 samples from 11 infants (period of sampling: J3 to J23). Among the 1772 TTGE bands detected, 440 corresponded to artifactual bands, mainly heteroduplexes. This result underlined the high frequency occurrence of PCR artifacts when bacterial community was analyzed. If they remained unrecognized, they could lead to overestimated diversity. A total of 93 bands (7\%) could not be analyzed because they did not correspond to bands present in the diversity ladder and because they were too faint to be cut and sequenced. Finally, 1239 bands were affiliated to a SpeciesLevel Operational Taxonomic Unit (SLOTU). Our approach combining sequencing and comparison to a diversity ladder allowed artifact exclusion and SLOTU affiliation for about $93 \%$ of the bands with a sequencing effort of only 189 bands. We identified 50 different SLOTUs that reflected the overall microbiota diversity in 30 patients. The number of SLOTUs per patient varied from 0 to 13 . The diversity was probably underestimated because among the 93 bands not affiliated to a SLOTU, 37 different distances of migration were distinguished. In a previous study associating TTGE and cloning/sequencing approaches, 288 clones were sequenced and 25 different SLOTUs were described [4]. A comprehensive culturebased study of the microbiota of preterm neonates of less than $1000 \mathrm{~g}$ surveyed during 30 days showed a total diversity of 20 bacterial species [19]. Comparatively with these previous approaches, we describe a wider bacterial diversity in stool samples of preterm neonates.

The 50 SLOTUs were distributed in 19 genera or families named Genus-Level Operational Taxonomic Unit 


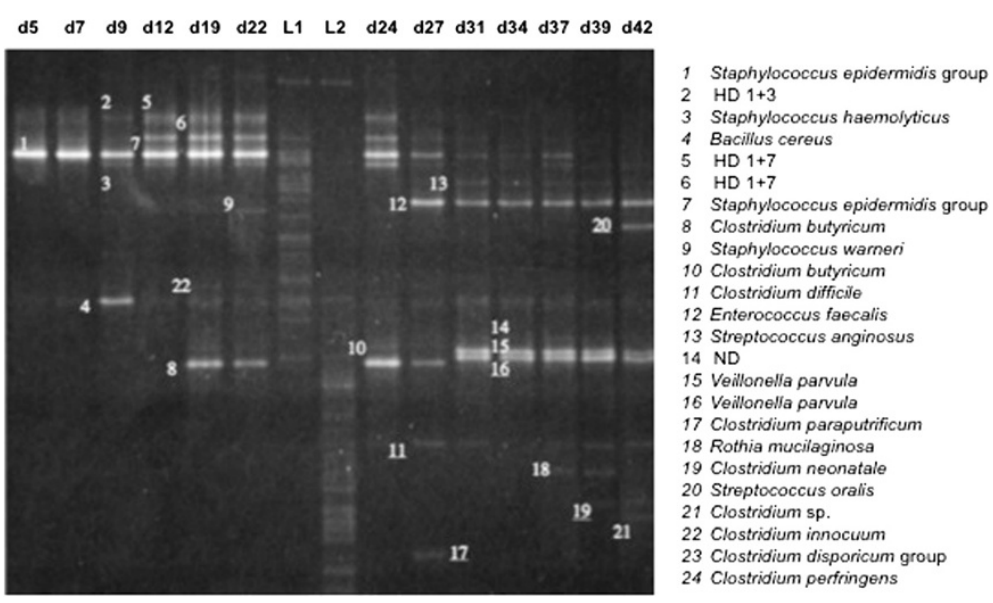

Figure 1 Representative TTGE gel obtained for the chronological follow-up of patient D from day 5 (d5) to day $\mathbf{4 5}$ (d45). Bands were identified with a number on the gel that corresponded to SLOTU identification. HD for heteroduplex band followed by the numbering of the bands forming the HD band. ND for not determined. L1 and L2 corresponded to the diversity ladders.

(GLOTU), which were defined on the basis of bacterial taxonomy (Table 1; Figure 2). The genera Escherichia, Enterobacter and Klebsiella were grouped in Enterobacteriaceae owing to the $16 \mathrm{~S}$ rRNA gene relatedness among the genera of this family. The species Clostridium innocuum was affiliated to Erysipelotrichaceae because it does not belong to the genus Clostridium despite confusing nomenclature. The TTGE bands were distributed in each GLOTU as presented in Figure 2. Seven GLOTUs represented from $1.5 \%$ to $53.6 \%$ of total TTGE bands, Staphylococcus, Clostridium Enterococcus, Veillonella, Enterobacteriaceae, Streptococcus and Bifidobacterium. Each other GLOTU represented 1\% or less of the total TTGE bands (Figure 2).

As expected, pyrosequencing approaches detected more SLOTUs but most of them belonged to minority populations, each representing less than $1 \%$ of the total diversity [35]. Again, higher genus-level diversity was reported with high-throughput sequencing methods revealing up to 365 genera in the fecal microbiota of premature infants $[7,10]$. However, LaTuga et al. [35] showed that 1 to 2 genera out of the 61 found in their study comprised over $90 \%$ of the sequences in most individual samples [35].

To determine the relative repartition of high-level taxa per patient, the GLOTUs were grouped in their corresponding phylum or class for the phylum Firmicutes to form PLOTUs (Phylum-Level Operational Taxonomic Units). The bacteria described belonged to the 6 following PLOTUS: phyla Actinobacteria, Proteobacteria, Fusobacteria and classes Bacilli, Clostridia and Negativicutes in the phylum Firmicutes. Although most patients carried only 2 to 4 PLOTUs, we observed important variations among patients (Figure 3). The Firmicutes represented the large majority of SLOTUs in all patients and 9 patients harboured only Firmicutes. Bacilli was the sole and generally predominating PLOTU found in all neonates and was the only PLOTU recovered in 3 patients. Beside Bacilli, Clostridia was the most represented PLOTU found in 21 neonates. Finally, Gram-positive bacteria largely dominated the bacterial community since they represented $88 \%$ of the identified SLOTUs.

High-throughput sequencing methods revealed higher diversity than we observed herein but the 3 dominant phyla (Firmicutes, Actinobacteria, Proteobacteria) were concordantly found $[5,7,10,35]$. However, discrepancies between studies were observed for the phylum Bacteroidetes, most often found as a rarely represented phylum while representing about $8 \%$ of the sequences in the study by Mai et al. [7]. Surprisingly, members of the phylum Fusobacteria found in our study were not reported by these sequencing-based studies [5,7,10,35]. The phylum diversity was not markedly higher in the gut microbiota of adults and infants. Ten phyla were detected in the stool specimens of the 242 adults included in the Human Microbiome Project but this number generally decreases to 3 to 4 phyla if each subject is considered [37].

In adults and weaning children, Bacteroidetes is the major bacterial phylum constituent of the gut microbiota followed by Firmicutes such as Eubacterium, Ruminococcus and Clostridium. In the extreme premature neonates studied herein, Firmicutes appeared the major component of the gut microbiota but Bacteroidetes were unrepresented (Figure 2). Members of Firmicutes differed from those described in adults since the class Bacilli with the genera Staphylococcus, Streptococcus and Enterococccus was the most represented. Members of the class Negativicutes were also well represented.

Finally, although PCR-TTGE lacks sensitivity in the detection of minority population, major GLOTUs and 
Table 1 Frequency and semi-quantitative estimation of OTUs within samples and infants

\begin{tabular}{|c|c|c|c|c|c|c|c|}
\hline \multirow[t]{2}{*}{ Species-level OTU $(n=50)$} & \multirow{2}{*}{$\begin{array}{l}\text { Genus and/or } \\
\text { family-level OTUs } \\
(n=19)\end{array}$} & \multirow{2}{*}{$\begin{array}{l}\text { Samples } \\
\text { with OTU } \\
n(\%)^{c}\end{array}$} & \multirow{2}{*}{$\begin{array}{l}\text { Infants } \\
\text { with OTU } \\
n(\%)^{d}\end{array}$} & \multirow{2}{*}{$\begin{array}{l}\text { Period of } \\
\text { detection } \\
\text { (day) }\end{array}$} & \multicolumn{3}{|c|}{$\begin{array}{l}\text { Semi-quantitative score } \\
\text { (band intensity) }\end{array}$} \\
\hline & & & & & $\begin{array}{l}1(+) n(\%) \\
\text { of bands }\end{array}$ & $\begin{array}{l}2(++) n(\%) \\
\text { of bands }\end{array}$ & $\begin{array}{l}3(+++) n(\%) \\
\text { of bands } \\
\end{array}$ \\
\hline $\begin{array}{l}\text { Staphylococcus epidermidis } \\
\text { group* }\end{array}$ & Staphylococcus & $268(75.7 \%)$ & $30(100 \%)$ & d3-d53 & $45(16.8 \%)$ & $67(25 \%)$ & $156(58.2 \%)$ \\
\hline Staphylococcus haemolyticus* & Staphylococcus & $185(52.3 \%)$ & $26(86.7 \%)$ & $d 4-d 51$ & $34(18.4 \%)$ & $69(37.3 \%)$ & $82(44.3 \%)$ \\
\hline Staphylococcus warneri* & Staphylococcus & $45(12.7 \%)$ & $16(53.3 \%)$ & d3-d33 & $10(22.2 \%)$ & $16(35.6 \%)$ & $19(42.2 \%)$ \\
\hline Staphylococcus hominis* & Staphylococcus & $13(13.7 \%)$ & $6(20 \%)$ & $d 7-d 45$ & $4(30.8 \%)$ & $4(30.8 \%)$ & $5(38.4 \%)$ \\
\hline Staphylococcus sp. & Staphylococcus & $6(1.7 \%)$ & $3(10 \%)$ & $d 3-d 25$ & $2(33.3 \%)$ & $3(50 \%)$ & $1(16.7 \%)$ \\
\hline Staphylococcus cohnii & Staphylococcus & $4(1.1 \%)$ & $1(3.3 \%)$ & $d 27-d 33$ & $4(100 \%)$ & 0 & 0 \\
\hline$N D^{b}$ & Not determined & $93(26.3 \%)$ & $24(80 \%)$ & d3-d56 & 60 (64.5\%) & $16(17.2 \%)$ & $17(18.3 \%)$ \\
\hline Enterococcus faecalis & Enterococcus & $98(27.7 \%)$ & $18(60 \%)$ & d3-d56 & $13(13.3 \%)$ & $19(19.4 \%)$ & $66(67.3 \%)$ \\
\hline Enterococcus durans group & Enterococcus & $7(2 \%)$ & $2(6.7 \%)$ & d31-d53 & $1(14.3 \%)$ & $2(28.6 \%)$ & $4(57.1 \%)$ \\
\hline Clostridium butyricum* & Clostridium/Clostridiaceae & $40(11.3 \%)$ & $12(40 \%)$ & d18-d53 & $8(20 \%)$ & $11(27.5 \%)$ & $21(52.5 \%)$ \\
\hline Clostridium difficile* & Clostridium/Clostridiaceae & $34(9.6 \%)$ & $11(36.7 \%)$ & $d 24-d 56$ & $14(41.2 \%)$ & $17(50 \%)$ & $3(8.8 \%)$ \\
\hline Clostridium neonatale & Clostridium/Clostridiaceae & $29(8.2 \%)$ & $10(33.3 \%)$ & d16-d53 & $12(41.4 \%)$ & $12(41.4 \%)$ & $5(17.2 \%)$ \\
\hline Clostridium perfringens & Clostridium/Clostridiaceae & $23(6.5 \%)$ & $9(30 \%)$ & d17-d50 & $8(34.8 \%)$ & $4(17.4 \%)$ & $11(47.8 \%)$ \\
\hline Clostridium sp. & Clostridium/Clostridiaceae & $9(2.5 \%)$ & $4(13.3 \%)$ & $\mathrm{d} 27-\mathrm{d} 42$ & $6(66.7 \%)$ & $1(11.1 \%)$ & $2(22.2 \%)$ \\
\hline Clostridium paraputrificum & Clostridium/Clostridiaceae & $5(1.4 \%)$ & $3(10 \%)$ & d15-d18 & $2(40 \%)$ & $2(40 \%)$ & $1(20 \%)$ \\
\hline Clostridium tertium & Clostridium/Clostridiaceae & $9(2.5 \%)$ & $3(10 \%)$ & $d 22-d 49$ & $3(33.3 \%)$ & $3(33.3 \%)$ & $3(33.3 \%)$ \\
\hline Clostridium disporicum group & Clostridium/Clostridiaceae & $5(1.4 \%)$ & $2(6.7 \%)$ & d15-d24 & $2(40 \%)$ & $2(40 \%)$ & $1(20 \%)$ \\
\hline Clostridium corinoforum & Clostridium/Clostridiaceae & $1(0.3 \%)$ & $1(3.3 \%)$ & d34 & $1(100 \%)$ & 0 & 0 \\
\hline Clostridium glycolicum* & Clostridium/Clostridiaceae & $1(0.3 \%)$ & $1(3.3 \%)$ & $\mathrm{d} 50$ & $1(100 \%)$ & 0 & 0 \\
\hline Clostridium favososporum & Clostridium/Clostridiaceae & $5(1.4 \%)$ & $1(3.3 \%)$ & $\mathrm{d} 31-\mathrm{d} 50$ & $3(60 \%)$ & $1(20 \%)$ & $1(20 \%)$ \\
\hline Clostridium symbosium group & Clostridium/Clostridiaceae & $2(0.6 \%)$ & $1(3.3 \%)$ & $d 21-d 27$ & 0 & $1(50 \%)$ & $1(50 \%)$ \\
\hline Sarcina ventriculi & Sarcina/Clostridiaceae & $1(0.3 \%)$ & $1(3.3 \%)$ & d17 & 0 & 0 & $1(100 \%)$ \\
\hline Escherichia coli* & Enterobacteriaceae & $22(6.2 \%)$ & $8(26.7 \%)$ & d6-d56 & $11(50 \%)$ & 0 & $11(50 \%)$ \\
\hline Klebsiella oxytoca & Enterobacteriaceae & $13(3.7 \%)$ & $4(13.3 \%)$ & d12-d56 & $4(30.8 \%)$ & $1(7.7 \%)$ & $8(61.5 \%)$ \\
\hline Klebsiella pneumoniae & Enterobacteriaceae & $3(0.8 \%)$ & $2(6.7 \%)$ & d39-d49 & 0 & 0 & $3(100 \%)$ \\
\hline Enterobacter cloacae & Enterobacteriaceae & $5(1.4 \%)$ & $1(3.3 \%)$ & d38-d56 & $1(20 \%)$ & 0 & $4(80 \%)$ \\
\hline Veillonella dispar & Veillonella & $31(8.8 \%)$ & $6(20 \%)$ & $d 4-d 56$ & $20(64.5 \%)$ & $3(9.7 \%)$ & $8(25.8 \%)$ \\
\hline Veillonella parvula & Veillonella & $9(2.5 \%)$ & $3(10 \%)$ & $\mathrm{d} 28-\mathrm{d} 45$ & $1(11.1 \%)$ & $5(55.6 \%)$ & $3(33.3 \%)$ \\
\hline Veillonella sp. & Veillonella & $7(2 \%)$ & $2(6.7 \%)$ & d19-d42 & $2(28.6 \%)$ & $2(28.6 \%)$ & $3(42.8 \%)$ \\
\hline Rothia mucilaginosa & Rothia & $10(2.8 \%)$ & $4(13.3 \%)$ & d37-d52 & $3(30 \%)$ & $3(30 \%)$ & $4(40 \%)$ \\
\hline Aquabacterium commune* & $\begin{array}{l}\text { Aquabacterium/ } \\
\text { Burkholderiales }\end{array}$ & $7(2 \%)$ & $4(13.3 \%)$ & $d 3-d 41$ & $5(71.4 \%)$ & $2(28.6 \%)$ & 0 \\
\hline Aquabacterium citratiphilum* & $\begin{array}{l}\text { Aquabacterium/ } \\
\text { Burkholderiales }\end{array}$ & $2(0.6 \%)$ & $1(3.3 \%)$ & $28-d 30$ & $1(50 \%)$ & $1(50 \%)$ & 0 \\
\hline Burkholderiales ND & Burkholderiales & $7(2 \%)$ & $1(3.3 \%)$ & d16-d33 & $5(71.4 \%)$ & $1(14.3 \%)$ & $1(14.3 \%)$ \\
\hline Streptococcus oralis group & Streptococcus & $4(1.1 \%)$ & $3(10 \%)$ & $d 24-d 50$ & $2(50 \%)$ & $1(25 \%)$ & $1(25 \%)$ \\
\hline Streptococcus salivarius & Streptococcus & $10(2.8 \%)$ & $2(6.7 \%)$ & d31-d56 & $5(50 \%)$ & $5(50 \%)$ & 0 \\
\hline Streptococcus anginosus & Streptococcus & $1(0.3 \%)$ & $1(3.3 \%)$ & d3 & 0 & 0 & $1(100 \%)$ \\
\hline $\begin{array}{l}\text { Streptococcus } \\
\text { oralis/parasanguinis }\end{array}$ & Streptococcus & $1(0.3 \%)$ & $1(3.3 \%)$ & $\mathrm{d} 49$ & $1(100 \%)$ & 0 & 0 \\
\hline $\begin{array}{l}\text { Streptococcus parasanguinis } \\
\text { group }\end{array}$ & Streptococcus & $1(0.3 \%)$ & $1(3.3 \%)$ & $d 42$ & 0 & $1(100 \%)$ & 0 \\
\hline Streptococcus sanguinis group & Streptococcus & $1(0.3 \%)$ & $1(3.3 \%)$ & $d 28$ & $1(100 \%)$ & 0 & 0 \\
\hline
\end{tabular}


Table 1 Frequency and semi-quantitative estimation of OTUs within samples and infants (Continued)

\begin{tabular}{|c|c|c|c|c|c|c|c|}
\hline Streptococcus thermophilus & Streptococcus & $5(1.4 \%)$ & $1(3.3 \%)$ & $\mathrm{d} 16-\mathrm{d} 28$ & $2(40 \%)$ & $1(20 \%)$ & $2(40 \%)$ \\
\hline Bacillus cereus group & Bacillus/Bacillaceae & $4(1.1 \%)$ & $4(13.3 \%)$ & d9-d56 & $3(75 \%)$ & 0 & $1(25 \%)$ \\
\hline Oceanobacillus sp. & $\begin{array}{l}\text { Oceanobacillus/ } \\
\text { Bacillaceae }\end{array}$ & $3(0.8 \%)$ & $1(3.3 \%)$ & d18-d24 & $3(100 \%)$ & 0 & 0 \\
\hline Bifidobacterium breve* & Bifidobacterium & $9(2.5 \%)$ & $2(6.7 \%)$ & d3-d49 & $3(33.3 \%)$ & $6(66.7 \%)$ & 0 \\
\hline Bifidobacterium longum & Bifidobacterium & $5(1.4 \%)$ & $2(6.7 \%)$ & $d 22-d 50$ & $3(60 \%)$ & $2(40 \%)$ & 0 \\
\hline Clostridium innocuum & Erysipelotrichaceae & $9(2.5 \%)$ & $1(3.3 \%)$ & d10-d36 & $3(33.3 \%)$ & $6(66.7 \%)$ & 0 \\
\hline Propionibacterium sp. & Propionibacterium & $3(0.8 \%)$ & $1(3.3 \%)$ & d18-d24 & $1(33.3 \%)$ & 0 & $2(66.7 \%)$ \\
\hline Propionibacterium acnes & Propionibacterium & $2(0.6 \%)$ & $1(3.3 \%)$ & $d 43-d 45$ & 0 & $2(100 \%)$ & 0 \\
\hline Sneathia sanguinegens & Sneathia & $2(0.6 \%)$ & $1(3.3 \%)$ & d3-d4 & $1(50 \%)$ & 0 & $1(50 \%)$ \\
\hline Pseudomonas sp. & Pseudomonas & $1(0.3 \%)$ & $1(3.3 \%)$ & d37 & 0 & $1(100 \%)$ & 0 \\
\hline Anaerococcus octavius & Anaerococcus & $2(0.6 \%)$ & $1(3.3 \%)$ & d32-d37 & 0 & $2(100 \%)$ & 0 \\
\hline $\begin{array}{l}\text { Corynebacterium } \\
\text { tuberculostearicum }\end{array}$ & Corynebacterium & $2(0.6 \%)$ & $1(3.3 \%)$ & d14-d15 & 0 & 2 (100\%) & 0 \\
\hline
\end{tabular}

${ }^{a}$ OTUs are indicated by main groups of decreasing occurence among the 30 preterm infants.

${ }^{b}$ ND, OTU not determined (not included in the total SLOTU number of 50): the group included bands with 37 distinct migration distances.

cNumber and \% of samples with OTU among the 354 samples, bold type indicates the species-level OTU mostly represented in samples within the corresponding genus and/or family-level OTU.

${ }_{\mathrm{d}}$ Number and \% of preterm infants with OTU among the 30 neonates, bold type indicates the species-level OTU mostly represented in neonates within the corresponding genus and/or family-level OTU.

${ }^{\text {e}}$ Bold type indicates the most frequent semi-quantitative score observed for the OTU within PCR-TTGE patterns.

*OTU identified in patient ZA with NEC.

PLOTUs were detected in accordance with molecular methods with higher throughput.

\section{Dynamics of extremely premature infant gut microbiota}

We studied the repartition of the 5 major GLOTUs per infant and per age post-delivery. The Figure 4A shows the relative proportion of infants displaying each major GLOTU and the weekly development of the GLOTUs' occurence. The only GLOTU shared by all the infants and found in more than $75 \%$ of the analysed samples was Staphylococcus spp. The percentage of infants colonized with enterococci, clostridia and enterobacteria increased over the survey period, markedly towards the $5^{\text {th }}$ week of life when the percentage of neonates carrying staphylococci began to decrease. The increase in members of the family Enterobacteriaceae was slightly delayed compared to the Gram-postive bacteria, enterococci and clostridia. In a previous study, we showed a global congruence between a semi-quantitative score calculated from intensity of TTGE bands and the number of colony-forming

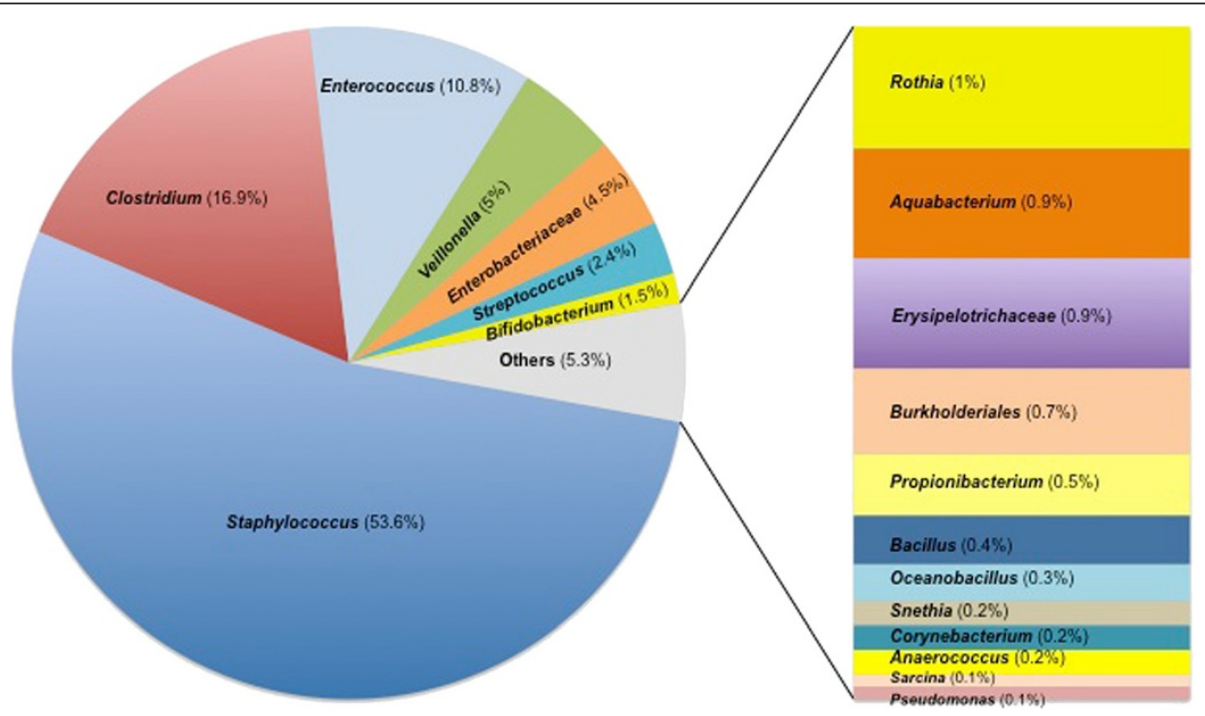

Figure 2 Repartition in 19 GLOTUs determinated from SLOTU-assigned bands obtained by PCR-TTGE from 340 stool samples. 


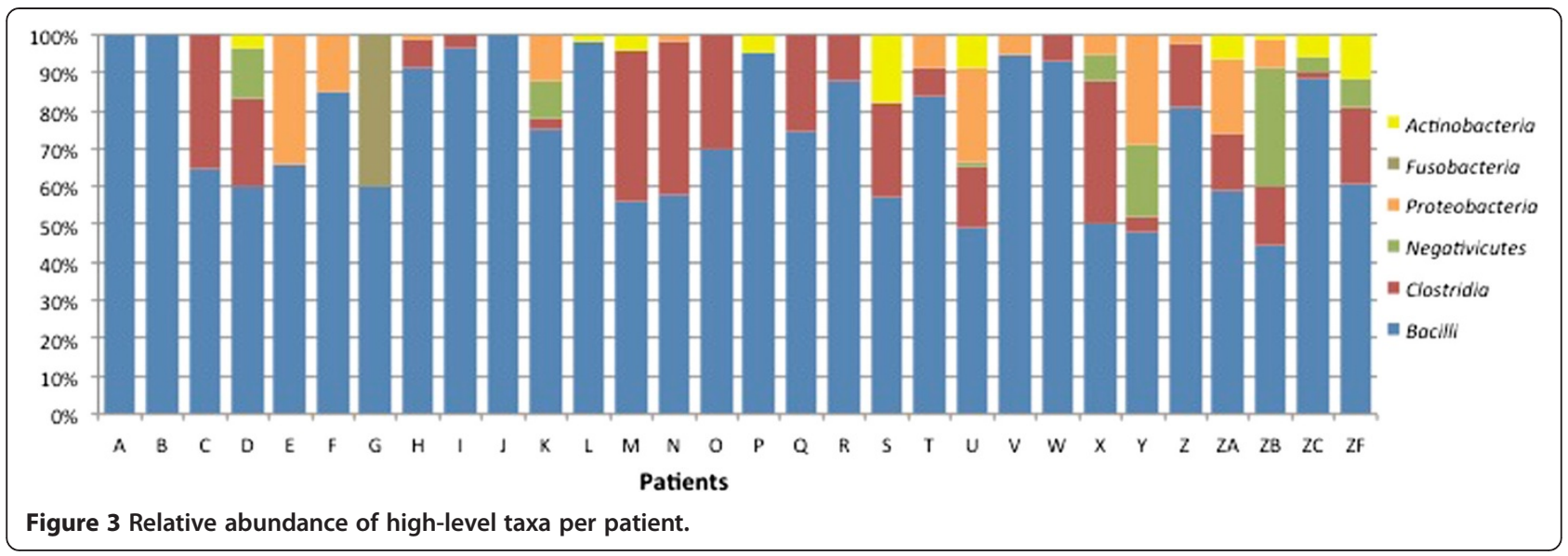

units (CFU), thereby validating the semi-quantitative approach based on band intensity [24]. We explored here the semi-quantitative dynamics of the major GLOTUs detected in the gut flora of the 30 neonates (Figure 4B). We showed that Staphylococcus, Enterococcus and Enterobacteriaceae successively dominated the very preterm neonate gut microbiota. Indeed, the semi-quantitative approach showed that Staphylococcus was the predominant population for the first 3 weeks of life followed by enterococci from the $4^{\text {th }}$ to the $6^{\text {th }}$ week of life and then by enterobacteria (Figure 4B). Semi-quantification of Clostridium showed they did not vary significantly over time (Figure 4B). Detailed microbiota composition over time is given for the 30 patients in the Additional file 1:

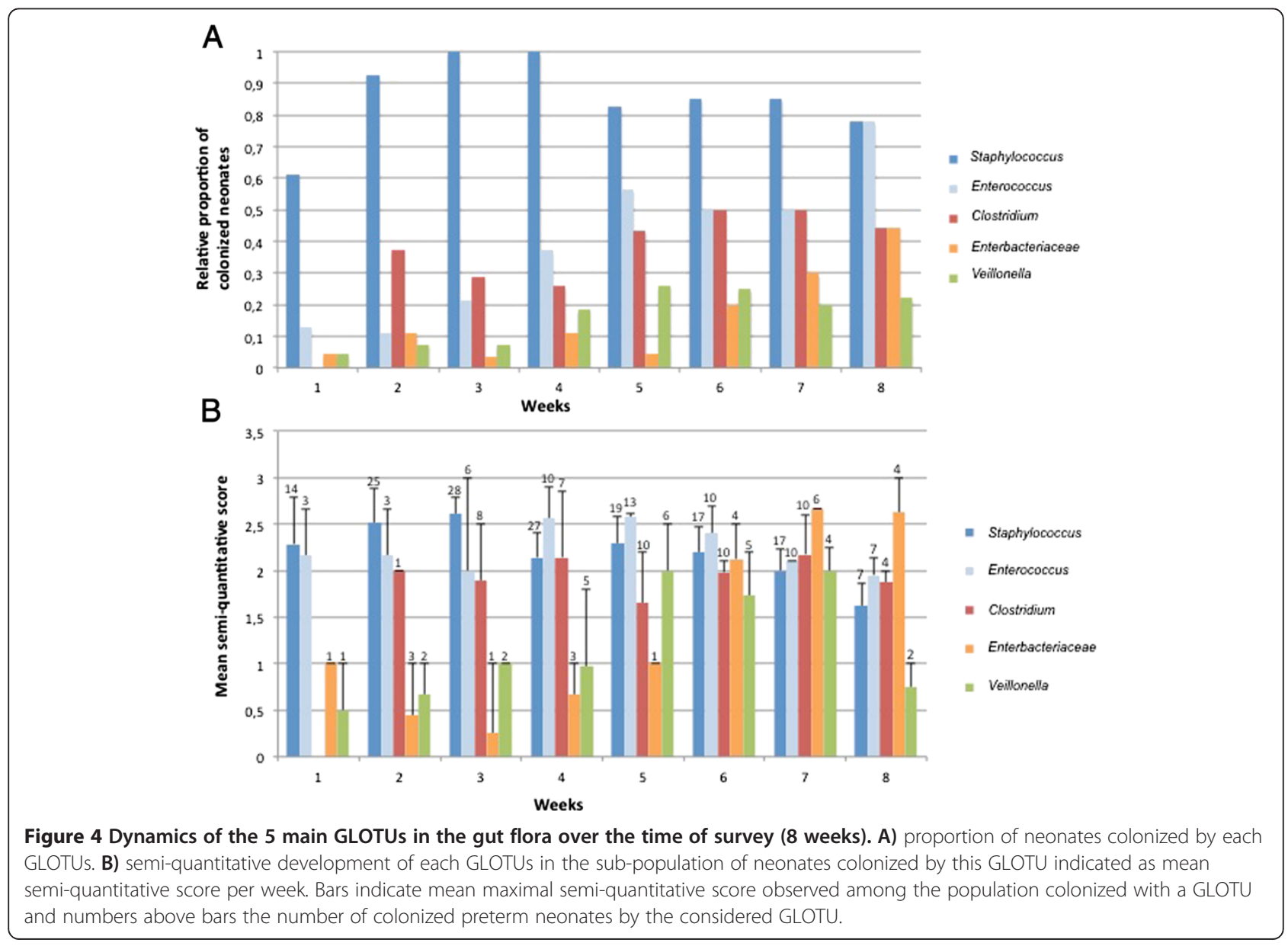


Table S1 together with semi-quantitative scores deduced from band intensity for each OTU occurrence (Additional file 1: Table S1). Less than $25 \%$ of the patients carried each minor GLOTU whatever the date after delivery and their qualitative or semi-quantitative (Additional file 1: Table S1) representation did not change significantly with the date of sampling.

\section{Staphylococci dominate the extremely premature infants gut microbiota}

The genus Staphylococcus represented 53.6\% of bands affiliated to a SLOTU (Figure 2). All infants carried Staphylococcus spp. at least once over the follow-up period. Up to four staphylococcal OTUs may be found in an infant ( $n=4,13.3 \%$ of the infants) but successive or concomitant colonization by 3 OTUs was observed in most infants $(\mathrm{n}=17,57 \%)$. For most neonates, staphylococci appeared during the first week of life and persisted up to the $8^{\text {th }}$ week post-delivery with a slight decrease in colonized infants after the $4^{\text {th }}$ week (Figure $4 \mathrm{~A}$ ). The semi-quantitative approach showed that staphylococci quantitatively dominate the gut microbiota up to the third week of life (Figure 4B). Most of the staphylococci were coagulase-negative staphylococci (CoNS) belonging to the $S$. epidermidis genomic group defined by DNADNA hybridization and $16 \mathrm{~S}$ rRNA gene phylogeny that included S. epidermidis, S. caprae, S. capitis, S. aureus and Staphylococcus warneri [38,39]. In this group of genetically very related species, $S$. warneri displayed particular TTGE behaviour and therefore could be identified separately. Different behaviours were observed for the CoNS species found in this study. Contrarily to other species, S. warneri was only found in the first month of life (Table 1). Colonization by a CoNS species may be transient as observed for $S$. warneri but also for $S$. hominis and Staphylococcus cohnii while S. epidermidis and $S$. haemolyticus usually appeared as persistent colonizers over the study period. After first detection, these two species were indeed found in more than $50 \%$ of the subsequent samples in 29 out of the 30 and in 20 out of the 26 infants colonized by each species, respectively.

CoNS predominance could be considered as a specific trait of the extremely premature infant gut microbiota fed by human pasteurised milk since staphylococci appeared as a minor or an unrepresented population in the gut community of adults $[40,41]$ or infants born at term, whatever their feeding pattern $[2,41]$. CoNS have received a marginal attention for their role in the early colonization of the premature and extremely premature infant gut microbiota. Few studies reported the detection of CoNS in neonate stools by culture, with controversial results concerning the load and the prevalence of these bacteria [3,42,43]. Molecular-based studies also detected staphylococci that seemed to dominate the extremely premature infant gut microbiota in the first weeks of life $[4,9]$. In these studies, predominance of CoNS was observed in only few cases due a low number of extremely preterm neonates included [9] or to the low sampling effort in each patient [4].

CoNS also retained attention since they are the major cause of LOS in neonatal intensive care unit (NICU) [44]. CoNS were supposedly acquired postnatally [44] and sometimes during nosocomial outbreaks [45]. The gut has recently been described as a reservoir of CoNS implicated in late-onset infections of extremely premature infants [46] and distortion in gut microbiota seemed to be related to LOS [7]. The breast-feeding origin of the neonate gut colonization by CoNS has been suspected because of the high prevalence of $S$. epidermidis in the milk of lactating women [47].

\section{Clostridium spp}

$16.9 \%$ of the TTGE bands obtained in this study corresponded to sequences affiliated to Clostridium spp. The genus Clostridium appeared as the most diverse since it was represented by 12 different SLOTUs (Table). Clostridium difficile (34 samples from 11 patients), Clostridium neonatale (29 samples from 10 patients), Clostridium butyricum (40 samples from 12 patients) and Clostridium perfringens (23 samples from 9 patients) were the most represented SLOTUs. Each other minor Clostridium SLOTU was found in 1 to 4 patients. Infants may be colonized by up to 5 clostridial OTUs $(n=4)$ but more frequently harboured $2(n=5)$ to $3(n=6)$ OTUs during the study period. Clostridium represented qualitatively a major group among the premature neonate gut microbial community (Figure $4 \mathrm{~A})$, colonizing $70 \%(\mathrm{n}=21)$ of the infants over the study period. The percent of Clostridium colonization of premature neonates is congruent with the result obtained by stool culture (79\%) [48]. The colonization began on the second week of life, then the number of colonized infants increased regularly from the $4^{\text {th }}$ to the $6^{\text {th }}$ week of life reaching $50 \%$ of neonates colonized by Clostridium spp. The semi-quantitative approach showed that Clostridium spp. represented a relatively important bacterial population as soon as they appeared and that bacterial load appeared stable over the survey period (Figure 4B). Considering OTUs shared by 2 infants or more, transient or persistent colonization was observed for the major clostridial OTUs (C. butyricum, $C$. difficile, $C$. neonatale and $C$. perfringens) and Clostridium tertium depending on the infants while Clostridium paraputrificum and Clostridium disporicum group appeared as transient colonizers only.

C. difficile is a recognized pathogen since the toxinogenic strains cause severe enterocolitis and antibioticassociated diarrhoea. The species represent up to $50 \%$ of the bacterial species isolated from infants, particularly 
from formula-fed infants [1]. In breast-fed infants $C$. difficile represented from $6 \%$ to $20 \%$ of the cultivated micro-organisms [1]. Healthy neonates may harbour $C$. difficile and its toxins without apparent pathologic consequences [42]. In our population, about $1 / 3$ of very preterm neonates were colonized by $\mathrm{C}$. difficile. "Clostridium neonatale" is a non-validated species described during a NICU outbreak where $20.8 \%$ of neonates carried the same "C. neonatale" strain [49]. We showed that out of an epidemic context, $1 / 3$ of our patients were colonized by $C$. neonatale. The role of $C$. neonatale and its specificity for the neonate microbiota need to be explored. Clostridium spp., particularly C. perfringens [9], C. difficile [50] and C. butyricum $[48,51]$ have been related to NEC. We showed that these OTUs frequently colonized the neonates included in this study. One patient developed a NEC, C. butyricum was detected twice, at the onset of the clinical signs and at day 31 after the onset of NEC (patient ZA).

\section{Enterococcus spp}

SLOTUs affiliated to the genus Enterococcus were among the most represented (10.8\%) and were found in 18 out of the 30 infants (60\%). However, diversity of enterococcal OTUs was rather low with 2 SLOTUs found during the study: Enterococcus faecalis which was the most represented and Enterococcus durans group (Table). Among the population, only 2 patients ( $6.7 \%$ of the infants) were successively or simultaneously colonized by these 2 SLOTUs. At the first week of life, $13 \%$ of the patients were colonized. The level of colonization increased regularly over time, about half of the patients being colonized at the $5^{\text {th }}$ week of life and up to $77 \%$ at the $8^{\text {th }}$ week (Figure $4 \mathrm{~A}$ ). The semi-quantitative evaluation showed that enterococci were the second dominating genus of the very premature gut microbiota after staphylococci up to the $3^{\text {rd }}$ week of life. Then, enterococci became quantitatively the major population during the following 3 weeks of life.

Despite inter-individual variations [2], enterococci were found among the main groups encountered in the gut microbiota of preterm infants [4] and represented one of the main groups during initial colonization in healthy infants in other molecular-based studies [27]. As observed herein, culture-based studies previously showed early enterococcal colonization that increased over time with a dynamic roughly similar to enterobacteria colonization (Figure 4A) [52], even if the quantitative increase in enterobacteria was delayed relative to enterococci (Figure 4B). However, in our population, the level of colonization was slightly lower than previously described in culture-based studies. For example, enterococcal colonization was shown by Hufnagel et al. (2007) [52] in $23 \%$ of the patients admitted to a NICU. In another instance, at the end of the first week of life, enterococci were isolated from stools of a large majority (87\%) of the preterm infants [17]. Persistant colonization was the most frequent finding for Enterococcus OTUs found in this study, observed in $83 \%$ of the infants harbouring $E$. faecalis and in the two infants colonized by $E$. durans group.

Both prematurity and low birth weight were statistically associated with enterococcal colonization on the first day of life [17]. Influence of the diet was also reported with significantly higher enterococcal counts for formula-fed infants compared to breast milk-fed infants [53]. Although enterococci were responsible for lifethreatening infections, enterococcal colonization on the first day of life was not associated with differences in the outcome of infants with respect to death and lifethreatening diseases [52].

\section{The genus Veillonella}

The genus Veillonella was the only representative of the class Negativicutes detected in this study. Five percent of the TTGE bands were affiliated to the genus Veillonella (Figure 2). Eight out of the 30 patients (26.6\%) were colonized with Veillonella at least once during the survey ( 5 infants by one OTU and 3 by 2 OTUs). About $5 \%$ of the neonates were colonized during the first week of life, this rate reaching about $20 \%$ from the $4^{\text {th }}$ week of life. Semi-quantitatively, high representation of Veillonella was observed between the $5^{\text {th }}$ and the $7^{\text {th }}$ week of life (Figure 4B). Large inter-individual variation was noted since Veillonella spp.-corresponding TTGE bands accounted for less than $5 \%$ to more than $30 \%$ of the generated bands depending on the patient (Figure 3). We showed here that members of the genus Veillonella could be present in gut microbiota of very premature infants, sometimes with high representation (patients D, Y and ZB in Figure 3) and persistent after the first colonization (patients D, K, X, Y and ZB) (Additional file 1: Table S1).

Veillonella spp. is part of several normal human microbiota including the fecal microbiota of healthy adults [54] and is predominant in the upper digestive tract [55]. Variations in the count of Veillonella spp. were previously noted depending on diet, pathology or antimicrobial treatment $[56,57]$. Veillonella may play a role in gut microbiota development at an early age [58] since they were shown to appear in neonate faeces on the first days of life [2,59], with significantly higher count in bottle-fed than in breast-fed children [1].

In oral flora, Veillonella spp. are early colonizers [60] establishing a nutrition chain with other bacteria [61] and are statistically associated with periodontal health [62]. Veillonella obtain energy from lactic acid produced by the streptococci as an end product of carbohydrate fermentation [63]. By analogy, one can expect that such a metabolic interaction between Veillonella spp. and lactic acid producers, notably staphylococci and streptococci, 
the main representatives of the major class Bacilli in this study, may occur in the digestive tract. The role and the impact of such a potential metabolic cooperation between early colonizers of the gut microbiota of premature infants are worth to be investigated.

\section{Enterobacteriaceae}

The family Enterobacteriaceae was represented by $4.5 \%$ of the TTGE bands observed in this study (Figure 2) and was demonstrated in 10 infants (33.3\%) during the study period. Most colonized patients $(n=6,60 \%)$ harbored a unique enterobacterial OTU while 3 OTUs were recovered during the follow-up of patient $\mathrm{Y}$. The representation of this family was lower than observed in culture-based studies [17] as well as in previous molecular-based studies, $36 \%$ of the clones detected in the study of Magne et al., [4] being affiliated to Enterobacteriaceae. In our patient population, enterobacteria were found in about 5 to $10 \%$ of the neonates during the 5 first weeks of life, then the rate of colonization increased to reach $45 \%$ of the neonates at the $8^{\text {th }}$ week (Figure 4A). Semi-quantitatively, we observed a rapid increase in the population after the $30^{\text {th }}$ day of life, enterobacteria being the dominating bacteria of the microbiota from the $7^{\text {th }}$ week of life (Figure 4B). Four SLOTUs were retrieved, Escherichia coli, Klebsiella pneumoniae, Klebsiella oxytoca and Enterobacter cloacae. E. coli was the main species represented, accounting for more than half of the SLOTUs of the family Enterobacteriaceae and was found in 8 preterm neonates. Klebsiella spp. and Enterobacter cloacae were found in 6 and 1 patients, respectively, and always showed a complex TTGE profile composed of several bands probably corresponding to $16 \mathrm{~S}$ rDNA intragenomic variability as previously described [29].

Most of the TTGE bands (86\%) corresponding to Enterobacteriaceae were observed in samples obtained after the $25^{\text {th }}$ day of life and it was only after the $30^{\text {th }}$ day of life, when the population quantitatively increased, that we observed Enterobacteriaceae in several successive samples. This suggests a durable implantation of enterobacteria after the first month of life of very premature neonates contrary to the early implantation described in healthy infant $[2,64]$ and in pre-term infant gut [3].

\section{Minority populations}

Fourteen minor GLOTUs, each representing less than $2.4 \%$ of the total GLOTUs (Figure 2), were detected in this study. Generally, less than $10 \%$ of the patients were colonized with such minor groups whatever the week of sampling (Additional file 1: Table S1) and semi-quantitative analysis showed that these groups were present at low load in the microbiota (data not shown). They included 23 SLOTUs, some of them being found in only one sample (Sarcina ventriculi, Bacillus sp. Oceanobacillus sp. etc.).
Others were able to colonize durably the neonate gut and were detected in several chronological samples in one or more patient. This was the case for Bifidobacterium breve (patient ZF), Bifidobacterium longum (patient U), Rothia mucilaginosa (patient S), Streptococcus salivarius (patients X and Y), and Streptococcus thermophilus (patient $\mathrm{T}$ ), which were previously described in neonate gut microbiota.

The genus Streptococcus appeared as a major group in the study of Magne et al. [4] whereas in accordance with our results streptococci were seldom detected in other studies [16,17,29]. Moreover, streptococcal OTUs were most often transient colonizers of the neonatal gut except for S. salivarius in patients $\mathrm{X}$ and $\mathrm{Y}$.

Bifidobacteria were detected in 4 patients (14 samples) and represented less than $1 \%$ of the TTGE bands analysed in this study. The rarity of bifidobacteria in our population of very preterm infants confirmed previous results [4]. Bifidobacteria were described as early and dominant colonizers of healthy full-term neonates specially breast-fed neonates $[1,58,65]$, but their colonization is delayed in pre-term infants $[3,16,17]$. In a recent study, probiotics, in the form of Bifidobacterium and Lactobacillus, fed enterally to very low birth weight preterm infants for 6 weeks were shown to reduce the incidence of death and necrotizing enterocolitis [66]. The low prevalence of bifidobacteria in very preterm neonate gut could be an additional argument for their use as probiotics. However, the patient ZA who developed a NEC was one of the four patients colonized by bifidobacteria in this study. We did not detect lactobacilli in this study.

To our knowledge, Burkholderiales (including Aquabacterium commune and Aquabacterium citraphilum), Sneathia sanguinegens and Rothia mucilaginosa were described here for the first time as colonizers of the neonate gut. Of note, $A$. commune and $A$. citraphilum have been found in four samples from the patient ZA, who developed a NEC. Some patients displayed very atypical microbiota; for instance, the patient $\mathrm{T}$ showed a persistent gut colonization by Streptococcus thermophilus and an unidentified Burkholderiales beside staphylococci over a 15-day period. No clinical or epidemiological particularity was noted for this neonate. The patient $G$ was colonized by staphylococci, Snethia sanguinegens (Fusobacteria), and an unidentified taxon and died at day 9 of life due to a non-digestive cause (Figure 3).

\section{Conclusions}

Today, pyrosequencing and other high-throughput sequencing methods allow the in-depth description of microbiota. However, high throughput metagenomics is until today limited to a relative low number of samples $[5,7,10,35]$, as examplified in recent matagenomic studies of the neonate gut microbiota. Despite low resolution, 
fingerprinting-based methods remain complementary of sequencing-based approaches because they allowed the follow-up of the dominant gut microbiota in larger cohorts of patients.

We describe here bacterial colonization dynamics in consecutive stool samples of 30 very premature infants. Gram-positive bacteria (staphylococci, enterococci and clostridia) represent the quantitatively dominant microbiota established in the neonate gut during the first month of life, staphylococci being the earliest colonizers found in a large majority of infants. Gram-negative bacteria (Enterobacteriaceae and Veillonella) established a delayed and inconstant colonization over the study period compared to Gram-positive bacteria.

Beside dominant microbiota, satellite taxa are numerous, generating a great interindividual variability in the composition and chronology of colonizing species, despite a monocentric recruitment, like in term neonates. According to the literature, this variability has to be related to multiple factors such as GA, mode of delivery, birth weight, per partum maternal antibiotherapy and early neonatal antibiotherapy. Thus, defining the normal gut-associated microbiota in preterm infants remains a challenge but is a prerequisite not only for future therapy aiming to intestinal microbiota modification but also for future research on intestinal diseases of the neonate.

\section{Methods}

\section{Population and stool sample collection}

We included 30 very preterm infants, born between 26 and 29 weeks of GA (median value $=27$ ) with a median birth weight of $950 \mathrm{~g}(760 \mathrm{~g}-1060 \mathrm{~g})$ and hospitalized in the NICU of the Montpellier university hospital. Stool samples were prospectively collected once to twice a week in each patient between day 3 and day 56 of life or until the last day of stay in the neonatal unit. Four to 15 samples were obtained for each patient (mean value $=$ 11.8). Other clinical characteristics recorded for the population were reported elsewhere [33]. Formal ethical approval was not required for this study but a written informed consent for participation in the study was obtained from the patient's parents.

\section{DNA extraction from stool sample}

Stool samples (50 mg, wet weight) were suspended in $1 \mathrm{~mL}$ of sterile DNA-free water and homogenized. The suspension was centrifuged at $10,000 \mathrm{~g}$ for $10 \mathrm{~min}$ at room temperature. The supernatants and the fat layers were removed. The pellets were suspended in $150 \mu \mathrm{l}$ of Tris-EDTA buffer and DNA was extracted using the MasterPure Gram positive DNA purification kit (Epicentre) according to supplier's instructions but with lysozym incubation prolonged to 16 hours.

\section{PCR-TTGE assays}

The V2-V3 region of the 16S rRNA gene was amplified with the primers HDA1 (5'-ACTCCTACGGGAGGCAG CAGT-3') and HDA2 (5'-GTATTACCGCGGCTGCTG GCA-3') (Ogier, 2002) giving a PCR product of about 233 bp. A GC-clamp 5'-CGCCCGGGGCGC GCCCCGG GCGGGGCGGGGGCACGGGGGG-3' was added at the 5 'side of the primer HDA1 for PCR-TTGE analysis. The PCR was performed with FastStart High fidelity PCR system (Roche). PCR and TTGE conditions were previously described [24].

\section{TTGE analysis and band identification}

The gel migration distance of TTGE bands was measured manually. Bands were assigned to OTUs either by comparison to a homemade "TTGE diversity» ladder which includes fingerprints of pure strains isolated from infant stools or by sequencing. The ladder was constructed as previously described [24]. Band comparisons were performed after gel standardization using three internal migration standard loaded with DNAs amplified from samples. Heteroduplex artifacts corresponding to chimeric amplification with each DNA strand coming from different bacteria in the community. Heteroduplex bands generally appeared as thin and/or faint bands at the top of the gel or nearly up to an intense band. Band sequencing confirmed their heterogeneous nature.

For sequencing, bands obtained from the TTGE gels were excised, washed three times in sterile distilled water, and incubated overnight in $50 \mu \mathrm{L}$ of elution buffer (Qiagen). The supernatant was used in a PCR experiment performed as described above with the primers HDA1 without GC-clamp and HDA2. Amplified DNA was then sequenced on an ABI 32 sequencer (Beckman Coulter Cogenics). The sequences were compared to the NCBI, RDPII and Greengenes databases to determine OTUs (Additional file 2). Each sequence was affiliated to a SLOTU that corresponded to a phylotype, i.e., a terminal node in $16 \mathrm{~S}$ rRNA-based phylogenetic analysis. In most cases, one SLOTU corresponded to one species, but it could correspond to a group of few species not separated in 16S rRNA gene phylogeny. Two phylotypes were affiliated to the same SLOTU when the sequence similarity was above 99\%. GLOTU and PLOTU corresponded to groups of SLOTU defined on the basis of the current taxonomy (http://www.ncbi.nlm.nih.gov/taxonomy).

\section{Diversity and dynamics data analysis}

As bacteriological data were collected at least once a week but at various days of age in the recruited infants, we reported them as a function of age using a weekbased scale. For each infant, the mean number of OTUs was computed for every week of age starting from 
delivery. The maximal number of species observed over the stool samples was also computed for each infant.

Semi-quantitative scoring was performed by visual inspection for each OTU using a four-point scale: 0 - no bacteria, 1 - few bacteria (+/weak band intensity), 2 - rather numerous bacteria $(++/$ moderate band intensity), 3 numerous bacteria (+++/bright band intensity) as previously described by Roudière et al. (2009) (24). For each neonate, a semi-quantitative score was calculated per week for each GLOTU corresponding to mean semiquantitative scores of the OTUs affiliated to the GLOTU. Finally, a mean semi-quantitative score was assessed per week for each GLOTU in the colonized population. The maximal semi-quantitative score observed for each GLOTU in each infant per week was also computed and a mean maximal score was calculated for the colonized patients. Colonization by an OTU was defined as either transient or persistent over the study period based on the number of positive samples $(\leq 50 \%$ and $>50 \%$, respectively) for the considered OTU after the initial OTU recovery.

\section{Nucleotide sequences accession number}

The partial sequences of $16 \mathrm{~S}$ rRNA gene obtained in this study have been deposited in the GenBank database under accession numbers (They will be provided upon acceptance of the article).

\section{Additional files}

Additional file 1: Table S1. Qualitative and semi-quantitative characteristics of gut colonization in the 30 preterm infants included in the study.

Additional file 2: Nucleotide sequences of the TTGE bands (fasta format).

\section{Competing interests}

The authors declare that they have no competing interests.

\section{Authors' contributions}

FA and LR carried out the diversity study and performed data formatting and interpretation. JCP conceived of the study and coordinated clinical research. AJ participated in the design of the study and performed patients' recruitment. AF interpreted data and helped to draft the manuscript. DN performed the statistical analysis and helped to draft the manuscript. TPB performed the statistical analysis. HM participated in the design of the study, in data interpretation and helped to draft the manuscript. EJB conceived of the study, coordinated microbiological experiments and write the manuscript. All authors read and approved the final manuscript.

\section{Acknowledgments}

Thanks are extended to Valérie Macioce, medical writer at the University Hospital of Montpellier, for English editing of the manuscript.

\section{Author details}

${ }^{1}$ Université Montpellier 1, UMR 5119 ECOSYM, Equipe Pathogènes et Environnements Unité de Bactériologie, U.F.R. des Sciences pharmaceutiques et biologiques, 15, Avenue Charles Flahault, BP 14491, Montpellier, Cedex 5 34093, France. ${ }^{2}$ Centre Hospitalier de Fréjus, Laboratoire de bactériologie, 240 avenue de Saint-Lambert BP 110 83608, Fréjus, France. ${ }^{3}$ Hospices Civil de
Lyon, Service de Néonatalogie, 103, Grande-Rue de la Croix-Rousse, Lyon, Cedex 04 69317, France. ${ }^{4}$ Centre Hospitalier Universitaire de Montpellier, Hôpital Arnaud de Villeneuve, Service de néo-natalogie, 371 Avenue du Doyen Gaston Giraud, Montpellier, Cedex 5 34295, France. ${ }^{5}$ Centre Hospitalier Régional Universitaire de Montpellier, Hôpital Lapeyronie, Département Urgences pédiatriques, 371, Avenue du Doyen Gaston Giraud, Montpellier, Cedex 5 34295, France. ${ }^{6}$ Centre Hospitalier Universitaire de Montpellier, Département d'Information Médicale, 371 Avenue du Doyen Gaston Giraud, Montpellier, Cedex 5 34295, France. ${ }^{7}$ Centre Hospitalier Universitaire de Montpellier, Hôpital Arnaud de Villeneuve, Laboratoire de Bactériologie, 371 Avenue du Doyen Gaston Giraud, Montpellier, Cedex 5 34295, France. ${ }^{8}$ Centre Hospitalier Universitaire de Montpellier, Laboratoire d'Hygiène hospitalière, 778, Rue de la Croix Verte, Montpellier 34000, France.

Received: 30 November 2014 Accepted: 11 December 2014

Published online: 31 December 2014

\section{References}

1. Benno Y, Sawada K, Mitsuoka T: The intestinal microflora of infants: composition of fecal flora in breast-fed and bottle-fed infants. Immunol 1984, 28:975-986.

2. Favier CF, Vaughan EE, de Vos WM, Akkermans DL: Molecular monitoring of succession of bacterial communities in human neonates. Appl Env Microbiol 2002, 68:219-226.

3. Sakata H, Yoshioka H, Fujita K: Development of the intestinal flora in very low birth weight infants compared to normal full-term newborns. Eur J Pediatr 1985, 144:186-190.

4. Magne F, Abely M, Boyer F, Morville P, Pochart P, Suau A: Low species diversity and high interindividual variability in faeces of preterm infants as revealed by sequences of $16 \mathrm{~S}$ rRNA genes and PCR-temporal temperature gradient gel electrophoresis profiles. FEMS Microbiol Ecol 2006, 57:128-138.

5. Chang JY, Shin SM, Chun J, Lee JH, Seo JK: Pyrosequencing-based molecular monitoring of the intestinal bacterial colonization in preterm infants. J Pediatr Gastroenterol Nutr 2011, 53:512-519.

6. Brook I: Microbiology and management of neonatal necrotizing enterocolitis. Am J Perinatol 2008, 25:111-118.

7. Mai V, Torrazza RM, Ukhanova M, Wang X, Sun Y, Li N, Shuster J, Sharma R, Hudak ML, Neu J: Distortions in development of intestinal microbiota associated with late onset sepsis in preterm infants. PLoS One 2013, 8:e52876.

8. Claud EC, Walker WA: Bacterial colonization, probiotics, and necrotizing enterocolitis. J Clin Gastroenterol 2008, 42:S46-S52.

9. de la Cochetiere MF, Piloquet H, des Robert C, Darmaun D, Galmiche JP, Roze JC: Early intestinal bacterial colonization and necrotizing enterocolitis in premature infants: the putative role of Clostridium. Pediatr Res 2004, 56:366-370.

10. Mai V, Young CM, Ukhanova M, Wang X, Sun Y, Casella G, Theriaque D, Li N, Sharma R, Hudak M, Neu J: Fecal microbiota in premature infants prior to necrotizing enterocolitis. PLoS One 2011, 6:e20647.

11. Deshpande G, Rao S, Patole S: Probiotics for prevention of necrotising enterocolitis in preterm neonates with very low birthweight: a systematic review of randomised controlled trials. Lancet 2007, 369:1614-1620.

12. Butel MJ, Roland N, Hibert A, Popot F, Favre A, Tessedre AC, Bensaada M, Rimbault A, Szylit O: Clostridial pathogenicity in experimental necrotising enterocolitis in gnotobiotic quails and protective role of bifidobacteria. J Med Microbiol 1998, 47:391-399.

13. Palmer C, Bik EM, DiGiulio DB, Relman DA, Brown PO: Development of the human infant intestinal microbiota. PLOS Biol 2007, 5:e177.

14. Gupta S, Morris JG Jr, Panigrahi P, Nataro JP, Glass Rl, Gewolb IH: Endemic necrotizing enterocolitis: lack of association with a specific infectious agent. Pediatr Infect Dis J 1994, 13:728-734.

15. Stark PL, Lee A: The microbial ecology of the large bowel of breast-fed and formula-fed infants during the first year of life. J Med Microbio/ 1982, 15:189-203.

16. Blakey JL, Lubitz L, Barnes GL, Bishop RF, Campbell NT, Gillam GL: Development of gut colonisation in pre-term neonates. J Med Microbiol 1982, 15:519-529.

17. Rotimi VO, Olowe SA, Ahmed I: The development of bacterial flora of premature neonates. J Hyg (Lond) 1985, 94:309-318. 
18. Hall SL, Hall RT, Barnes WG, Riddell SW, Meng L, Parisi JT, Kilbride HW, Maulik D: Relationship of maternal to neonatal colonization with coagulase-negative staphylococci. Am J Perinatol 1990, 7:384-388.

19. Gewolb IH, Schwalbe RS, Taciak VL, Harrison TS, Panigrahi P: Stool microflora in extremely low birthweight infants. Arch Dis Child Fetal Neonatal 1999, 80:F167-F173.

20. Hällström M, Eerola E, Vuento R, Janas M, Tammela O: Effects of mode of delivery and necrotising enterocolitis on the intestinal microflora in preterm infants. Eur J Clin Microbiol Infect Dis 2004, 23:463-470.

21. Butel MJ, Suau A, Campeotto F, Magne F, Aires J, Ferraris L, Kalach N, Leroux B, Dupont C: Conditions of bifidobacterial colonization in preterm infants: a prospective analysis. J Ped Gastroentero/ 2007, 44:577-582.

22. Rougé $C$, Piloquet $H$, Butel MJ, Berger B, Rochat F, Ferraris L, Des Robert C, Legrand A, de la Cochetière MF, N'Guyen JM, Vodovar M, Voyer M, Darmaun D, Rozé JC: Oral supplementation with probiotics in very-lowbirth-weight preterm infants: a randomized, double-blind, placebocontrolled trial. Am J Clin Nutr 2009, 89:1828-1835.

23. Björkström MV, Hall L, Söderlund S, Håkansson EG, Håkansson S, Domellöf M: Intestinal flora in very low-birth weight infants. Acta Paediatr 2009, 98:1762-1767

24. Roudière L, Jacquot A, Marchandin H, Aujoulat F, Devine R, Zorgniotti I, Jean-Pierre H, Picaud JC, Jumas-Bilak E: Optimized PCR-Temporal Temperature GelElectrophoresis compared to cultivation to assess diversity of gut microbiota in neonates. J Microbiol Methods 2009, 79:156-165.

25. Campeotto F, Suau A, Kapel N, Magne F, Viallon V, Ferraris L, WaligoraDupriet AJ, Soulaines P, Leroux B, Kalach N, Dupont C, Butel MJ: A fermented formula in pre-term infants: clinical tolerance, gut microbiota, downregulation of faecal calprotectin and up-regulation of faecal secretory lgA. Br J Nutr 2011, 22:1-10.

26. Zoetendal EG, Vaughan EE, de Vos WM: A microbial world within us. Mol Microbiol 2006, 59:1639-1650

27. Wang Y, Hoenig JD, Malin KJ, Qamar S, Petrof EO, Sun J, Antonopoulos DA Chang EB, Claud EC: 16S rRNA gene-based analysis of fecal microbiota from preterm infants with and without necrotizing enterocolitis. ISME J 2009, 3:944-954

28. Rougé C, Goldenberg O, Ferraris L, Berger B, Rochat F, Legrand A, Göbel UB, Vodovar M, Voyer M, Rozé JC, Darmaun D, Piloquet H, Butel MJ, de La Cochetière MF: Investigation of the intestinal microbiota in preterm infants using different methods. Anaerobe 2010, 16:362-370.

29. Millar MR, Linton CJ, Cade A, Glancy D, Hall M, Jalal H: Application of $16 \mathrm{~S}$ RNA gene PCR to study bowel flora of preterm infants with and without necroziting enterocolitis. J Clin Microbiol 1996, 34:2506-2510.

30. Schwiertz A, Gruhl B, Löbnitz M, Michel P, Radke M, Blaut M: Development of the intestinal bacterial composition in hospitalized preterm infants in comparison with breast-fed, full-term infants. Pediatr Res 2003, 54:393-399.

31. Mshvildadze M, Neu J, Shuster J, Theriaque D, Li N, Mai V: Intestinal microbial ecology in premature infants assessed with non-culture-based techniques. J Pediatr 2010, 156:20-25

32. Ogier JC, Son O, Gruss A, Tailliez P, Delacroix-Buchet A: Identification of the bacterial microflora in dairy products by temporal temperature gradient gel electrophoresis. App/ Environ Microbiol 2002, 68:3691-3701.

33. Jacquot A, Neveu D, Aujoulat F, Mercier G, Marchandin H, Jumas-Bilak E, Picaud JC: Dynamics and clinical evolution of bacterial gut microflora in extremely premature patients. J Pediatr 2011, 158:390.

34. Morowitz MJ, Denef VJ, Costello EK, Thomas BC, Poroyko V, Relman DA, Banfield JF: Strain-resolved community genomic analysis of gut microbial colonization in a premature infant. Proc Natl Acad Sci U S A 2011, 108:1128-1133.

35. LaTuga MS, Ellis JC, Cotton CM, Goldberg RN, Wynn JL, Jackson RB, Seed PC: Beyond bacteria: a study of the enteric microbial consortium in extremely low birth weight infants. PLoS One 2011, 6:e27858.

36. Sharon I, Morowitz MJ, Thomas BC, Costello EK, Relman DA, Banfield JF: Time series community genomics analysis reveals rapid shifts in bacterial species, strains, and phage during infant gut colonization. Genome Res 2013, 23(1):111-120.

37. Human Microbiome Project Consortium: Structure, function and diversity of the healthy human microbiome. Nature 2012, 486:207-214.

38. Ghebremedhin B, Layer F, König W, König B: Genetic classification and distinguishing of Staphylococcus species based on different partial gap, $16 \mathrm{~S}$ rRNA, hsp60, rpoB, sodA, and tuf gene sequences. J Clin Microbiol 2008, 46(3):1019-1025.
39. Schleifer KH, MeAyer SA, Rupprecht M: Relatedness among coagulasenegative staphylococci deoxyribonucleic acid reassociation and comparative immunological studies. Arch Microbiol 1979, 122(1):93-101.

40. Eckburg PB, Bik EM, Bernstein CN, Purdom E, Dethlefsen L, Sargent M, Gill SR, Nelson KE, Relman DA: Diversity of the Human Intestinal Microbial Flora. Science 2005, 308:1635-1638.

41. Kurokawa K, Itoh T, Kuwahara T, Oshima K, Toh H, Toyoda A, Takami H, Morita H, Sharma VK, Srivastava TP, Taylor TD, Noguchi H, Mori H, Ogura Y, Ehrlich DS, Itoh K, Takagi T, Sakaki Y, Hayashi T, Hattori M: Comparative metagenomics revealed commonly enriched gene sets in human gut microbiomes. DNA Res 2007, 14:169-181.

42. Mackie Rl, Sghir A, Gaskins HR: Developmental microbial ecology of the neonatal gastrointestinal tract. Am J Clin Nutr 1999, 69:1035S-1045S.

43. Kafarskaia LI, Volodin NN, Efimov BA, Afanas'ev SS, Shkoporov AN: Peculiarities of microbial colonization of the intestinal tract in newborns and pre-term infants in intensive care units] [Article in Russian. Vestn Ross Akad Med Nauk 2006, 1:10-15.

44. Rønnestad A, Abrahamsen TG, Medbø S, Reigstad H, Lossius K, Kaaresen PI, Engelund IE, Irgens LM, Markestad T: Septicemia in the first week of life in a Norwegian national cohort of extremely premature infants. Pediatrics 2005, 115:e262-e268.

45. Foka A, Chini V, Petinaki E, Kolonitsiou F, Anastassiou ED, Dimitracopoulos G, Spiliopoulou I: Clonality of slime-producing methicillin-resistant coagulase-negative staphylococci disseminated in the neonatal intensive care unit of a university hospital. Clin Microbiol Infect 2006, 12:1230-1233.

46. Soeorg H, Huik K, Parm U, IImoja ML, Metelskaja N, Metsvaht T, Lutsar I: Genetic Relatedness of Coagulase-Negative Staphylococci from Gastrointestinal Tract and Blood of Preterm Neonates with Late-Onset Sepsis. Pediatr Infect Dis J 2012, Oct 17. [Epub ahead of print]

47. Jimenez E, Delgado S, Maldonado A, Arroyo R, Albújar M, García N, Jariod M, Fernández L, Gómez A, Rodríguez JM: Staphylococcus epidermidis: a differential trait of the fecal microbiota of breast-fed infants. BMC Microbiol 2008, 10:138-143.

48. Ferraris L, Butel MJ, Campeotto F, Vodovar M, Rozé JC, Aires J: Clostridia in premature neonates' gut: incidence, antibiotic susceptibility, and perinatal determinants influencing colonization. PLoS One 2012, 7:e30594.

49. Alfa MJ, Robson D, Davi M, Bernard K, Van Caeseele P, Harding GK: An outbreak of necrotizing enterocolitis associated with a novel clostridium species in a neonatal intensive care unit. Clin Infect Dis 2002, 35:S101-S105.

50. Han VK, Dayed H, Chance GW, Brabyn DG, Shaheed WA: An outbreak of Clostridium difficile necrotizing enterocolitis: a case for oral vancomycin therapy? Pediatrics 1983, 71:935-941.

51. Gothefors L, Blenkarn I: Clostridium butyricum and necrotising enterocolitis. Lancet 1978, 1:52-53.

52. Hufnagel M, Liese $C$, Loescher $C$, Kunze M, Proempeler $H$, Berner R, Krueger $M$ : Enterococcal colonization of infants in a neonatal intensive care unit: associated predictors, risk factors and seasonal patterns. BMC Infect Dis 2007, 7:107-128.

53. Rubaltelli FF, Biadaioli $R$, Pecile $P$, Nicoletti $P$ : Intestinal flora in breast- and bottle-fed infants. J Perinat Med 1998, 26:186-191.

54. Quintanilha AG, Zilberstein B, Santos MA, Pajecki D, Moura EG, Alves PR, Maluf-Filho F, Cecconello I: A novel sampling method for the investigation of gut mirobiota. World J Gastroenterol 2007, 13:3990-3995.

55. Zilberstein B, Quintanilha AG, Santos MA, Pajecki D, Moura EG, Alves PR, Maluf Filho F, de Souza JA, Gama-Rodrigues J: Digestive tract microbiota in healthy volunteers. Clinics 2007, 62:47-54.

56. Albert MJ, Bhat P, Rajan D, Maiya PP, Pereira SM, Baker SJ: Faecal flora of South Indian infants and young children in health and with acute gastroenteritis. J Med Microbiol 1978, 11:137-143.

57. Malinen E, Rinttilä T, Kajander K, Mättö J, Kassinen A, Krogius L, Saarela M, Korpela R, Palva A: Analysis of the fecal microbiota of irritable bowel syndrome patients and healthy controls with real-time PCR. Am J Gastroenterol 2005, 100:373-382.

58. Harmsen HJ, Wildeboer-Veloo AC, Raangs GC, Wagendorp AA, Klijn N, Bindels JG, Welling GW: Analysis of intestinal flora development in breastfed and formula-fed infants by using molecular identification and detection methods. J Pediatr Gastroenterol Nutr 2000, 30:61-67.

59. Rotimi VO, Duerden Bl: The development of the bacterial flora in normal neonates. J Med Microbiol 1981, 14:51-62. 
60. Könönen E, Kanervo A, Takala A, Asikainen S, Jousimies-Somer H: Establishment of oral anaerobes during the first year of life. J Dent Res 1999, 78:1634-1639

61. Egland PG, Palmer RJ Jr, Kolenbrander PE: Interspecies communication in Streptococcus gordonii-Veillonella atypica biofilms: signaling in flow conditions requires juxtaposition. Proc Natl Acad Sci U S A 2004, 101:16917-16922.

62. Kumar PS, Leys EJ, Bryk JM, Martinez FJ, Moeschberger ML, Griffen AL: Changes in periodontal health status are associated with bacterial community shifts as assessed by quantitative $16 \mathrm{~S}$ cloning and sequencing. J Clin Microbiol 2006, 44:3665-3673.

63. Diaz PI, Chalmers NI, Rickard AH, Kong C, Milburn CL, Palmer RJ Jr, Kolenbrander PE: Molecular characterization of subject-specific oral microflora during initial colonization of enamel. Appl Environ Microbiol 2006, 72:2837-2848

64. Park HK, Shim SS, Kim SY, Park JH, Park SE, Kim HJ, Kang BC, Kim CM: Molecular analysis of colonized bacteria in a human newborn infant gut. J Microbiol 2005, 43:345-353.

65. Turroni F, Peano C, Pass DA, Foroni E, Severgnini M, Claesson MJ, Kerr C, Hourihane J, Murray D, Fuligni F, Gueimonde M, Margolles A, De Bellis G, OToole PW, van Sinderen D, Marchesi JR, Ventura M: Diversity of bifidobacteria within the infant gut microbiota. PLoS One 2012, 7:e36957.

66. Lin HC, Hsu CH, Chen HL, Chung MY, Hsu JF, Lien Rl, Tsao LY, Chen CH, Su $\mathrm{BH}$ : Oral probiotics prevent necrotizing enterocolitis in very low birth weight preterm infants: a multicenter, randomized, controlled trial. Pediatrics 2008, 122:693-700.

\section{Submit your next manuscript to BioMed Central and take full advantage of:}

- Convenient online submission

- Thorough peer review

- No space constraints or color figure charges

- Immediate publication on acceptance

- Inclusion in PubMed, CAS, Scopus and Google Scholar

- Research which is freely available for redistribution 